Research Article

\title{
Effect of Osmotic Pressure on Migration Behavior of nZnO in GCLs
}

\author{
Ping Yang, ${ }^{1}$ Tao Jiang $\mathbb{D D}^{2}$ Youlong Zhang, ${ }^{3}$ and Zhicheng $\mathrm{Li}^{4}$ \\ ${ }^{1}$ Key Laboratory of Geotechnical and Underground Engineering of Ministry of Education, Tongji University, Shanghai, China \\ ${ }^{2}$ Department of Geotechnical Engineering, Tongji University, Shanghai, China \\ ${ }^{3}$ China Aviation International Construction and Investment Co. Ltd, Beijing, China \\ ${ }^{4}$ Department of Geotechnical Engineering, Tongji University, Shanghai, China \\ Correspondence should be addressed to Tao Jiang; 1530834@tongji.edu.cn
}

Received 14 June 2018; Revised 21 August 2018; Accepted 18 September 2018; Published 16 October 2018

Academic Editor: Annan Zhou

Copyright (C) 2018 Ping Yang et al. This is an open access article distributed under the Creative Commons Attribution License, which permits unrestricted use, distribution, and reproduction in any medium, provided the original work is properly cited.

\begin{abstract}
The migration of zinc oxide nanoparticles (nZnO) in geosynthetic clay liners (GCLs) under different osmotic pressures was conducted using a self-developed geosynthetic clay liner osmometer. The effects of the osmotic pressure on the migration behavior of $\mathrm{nZnO}$ in GCLs were analyzed. The results showed that, with an increase of osmotic pressure, the retention rate of $\mathrm{nZnO}$ increased greatly, the particle size increased, the stability of the soliquoid declined, GCLs pores were compressed, the infiltration coefficient of GCLs reduced, and the interception effect of GCLs on nZnO particles strengthened. The two-site model can simulate the migration behavior of $\mathrm{nZnO}$ in GCLs very well. The correlativity between the maximum migration distance $\left(L_{\max }\right)$ of $\mathrm{nZnO}$ in GCLs and the osmotic pressure was negative.
\end{abstract}

\section{Introduction}

Zinc oxide nanopartilces (nZnO) are a high-performance inorganic product and are currently one of the most widely used engineered nanoparticles (ENPs) in the world $[1,2]$. However, Collins [3] reported that $\mathrm{nZnO}$ can affect the survival of organisms in the soil and can even change their community structure. At concentrations of 50 and $100 \mathrm{mg} / \mathrm{L}$, $\mathrm{nZnO}$ exhibited cytotoxicity in Neuro-2A cells [4]. Moreover, $\mathrm{nZnO}$ can reach the membranes of human aortic endothelial cells (HAECs) and can be absorbed. At a concentration of $10 \mathrm{mg} / \mathrm{L}, \mathrm{nZnO}$ induced a conspicuous inflammatory response in HAECs. At higher concentrations, $\mathrm{nZnO}$ could lead to HAEC necrosis [5]. The toxic effects of $\mathrm{nZnO}$ on human lung adenocarcinoma cells (A549) were concentration-dependent and time-dependent [6]. Deng [7] holded that the cytotoxicity of $\mathrm{nZnO}$ was mainly caused by the dissolved zinc ions.

Solid waste landfill leaking is a key path for nanoparticles to enter the natural environment [8]. With increasing application of nano materials, large amounts of nanoparticles have entered landfills as three types of waste [9]. Nanoparticles in liquid waste can easily enter the leachate of landfill. Bolyard et al. [10] and Khan et al. [11] have found that nanoparticles suspended in leachate can migrate successfully through garbage soil. Current studies have mostly adopted column elution tests to simulate nanoparticle migration in the soil. The testing systems mainly consisted of a suspension of $\mathrm{nZnO}$ particles ( $\mathrm{nZnO}$ suspension) and a porous medium [12]. The porous medium was typically composed of quartz sand, silica sand, and glass beads, which serve as a simplified replacement of natural soil. The physical and chemical properties of the porous medium are distinctively different from those of natural soil. Research results showed that the migration of carbon nanotubes was weaker in quartz sand than in glass beads [13]. The smaller the particle size of quartz sand is, the weaker the migration of nanoparticles is. When the particle size of quartz sand decreased from $0.106 \mathrm{~mm}$ to $0.043 \mathrm{~mm}$, the concentration of nanoparticles in the effluent declined by $60 \%$ [14]. Similar patterns have also been observed in $\mathrm{nTiO}_{2}$ and $\mathrm{nAg}$ in subsequent studies [15]. The interception ratio of nC60 in 
clay-containing soil specimens was far higher than that in quartz sand and glass beads. The interception in soil specimens was irreversible [16]. The findings indicated that soil properties exert significant influence on nanoparticle migration in soil. In addition, specific chemical properties of the suspension (e.g., ionic strength, organic matter content, surface active agents, and $\mathrm{pH}$ values) can indirectly affect the migration behavior of nanoparticles in a porous medium by influencing nanoparticle scattering and suspension stability $[17,18,19,20]$.

Aforementioned research on the migration of nanoparticles in ideal porous media (e.g., glass beads and quartz sand) or sand obtained preliminary results [21, 22]. The NPs migration and sorption processes are related to the soil properties differentiation [23]. Until now, no published studies have considered the influence of osmotic pressure on the migration properties of nanoparticles in a porous medium. A previous test conducted at landfill sites indicated that the water level of leachate inside landfills could be as high as $20 \mathrm{~m}-30 \mathrm{~m}$ [24]. Geosynthetic clay liner (GCL) was used as the last barrier preventing garbage leachate to enter the natural environment [25]. Whether can GCLs effectively intercept nanoparticles under high osmotic pressure? Therefore, it is an important issue that how osmotic pressure in landfill leachate impacts on migration behaviors of $\mathrm{nZnO}$ particles from GCLs to the groundwater.

\section{Experimental Materials and Methods}

\subsection{Material}

2.1.1. Geosynthetic Clay Liner. The GCL was prepared by stitching sodium bentonite particles between two layers of geotextiles. According to the data provided by the GCL manufacturer, the bottom layer was woven geotextile with a unit mass of $221 \mathrm{~g} / \mathrm{m}^{3}$, the top layer was nonwoven geotextile with a unit mass of $112 \mathrm{~g} / \mathrm{m}^{3}$, and the middle layer was bentonite. The performance of GCL and properties of bentonite are shown in Tables 1 and 2, respectively. The structural representation of the GCL is shown in Figure 1.

2.1.2. Preparation of the $\mathrm{nZnO}$ Suspension. $\mathrm{nZnO}$ particles were synthesized by a solid reaction process in this experiment. The specific processes are as follows:

(1) After a specific amount of nZnO had been scattered in an adequate amount of deionized water, the mixture was subjected to an ultrasonic crusher. The $\mathrm{nZnO}$ suspension achieved optimal scattering when the frequency, temperature, and time of the ultrasonic crusher were set at $28 \mathrm{kHz}, 50^{\circ} \mathrm{C}$, and $25 \mathrm{~min}$, respectively [26].

(2) The experiment employed inductively coupled plasma mass spectrometry (ICP) to measure the concentrations of $\mathrm{nZnO}$ suspensions. When the concentrations of elements differed, the suspensions emitted characteristic lights of varying intensity. Quantitative analysis was conducted using this property. The measuring process included the
TABle 1: Basic performance of GCLs.

\begin{tabular}{lc}
\hline Parameters & \\
\hline Mass per unit area $\left(\mathrm{kg} / \mathrm{m}^{2}\right)$ & 5.56 \\
Thickness $(\mathrm{mm})$ & 6.78 \\
Longitudinal breaking strength $(\mathrm{kN} / \mathrm{m})$ & 11.85 \\
Transverse breaking strength $(\mathrm{kN} / \mathrm{m})$ & 10.28 \\
Longitudinal breaking elongation $(\%)$ & 19.50 \\
Transverse breaking elongation $(\%)$ & 10.67 \\
Vertical permeability coefficient $(\mathrm{m} / \mathrm{s})$ & $2.69 \times 10^{-9}$ \\
Sodium bentonite content $\left(\mathrm{kg} / \mathrm{m}^{2}\right)$ & 5.32 \\
\hline
\end{tabular}

TABle 2: Basic properties of bentonite.

\begin{tabular}{lcc}
\hline & Montmorillonite & 67 \\
Mineral composition (\%) & Kaolinite & 14 \\
& Illite & 12 \\
& Orthoclase & 4 \\
& Quartz & 2 \\
\hline & $\mathrm{SiO}_{2}$ & 57.2 \\
& $\mathrm{Al}_{2} \mathrm{O}_{3}$ & 16.5 \\
& $\mathrm{CaO}$ & 3.4 \\
& $\mathrm{TiO}_{2}$ & 0.8 \\
Chemical composition (\%) & $\mathrm{Fe}_{2} \mathrm{O}_{3}$ & 5.7 \\
& $\mathrm{Na}_{2} \mathrm{O}$ & 3.3 \\
& $\mathrm{~K}_{2} \mathrm{O}$ & 0.7 \\
& $\mathrm{MgO}^{2}$ & 3.7 \\
\hline & $\mathrm{Na}^{+}$ & 0.445 \\
& $\mathrm{~K}^{+}$ & 0.010 \\
Ion exchange capacity (mmol/g) & $\mathrm{Ca}^{2+}$ & 0.159 \\
& $\mathrm{Mg}^{2+}$ & 0.017 \\
\hline Initial water content (\%) & & 17.0 \\
\hline Initial thickness (mm) & & 6.65 \\
\hline pH & & $9.89 \sim 10.67$ \\
\hline
\end{tabular}

following steps: (i) tetraacetic acid digestion to process the dispersion (the acid converted $\mathrm{nZnO}$ to zinc ions; the acid also dissolved soil and other impurities); (ii) ICP to measure the concentration of zinc ions and to calculate the concentration of $\mathrm{nZnO}$ suspension; and (iii) ZetaPALS to measure the zeta potential of the solution. The zeta potential is a measurement of the intensity of mutual repulsion or attraction among particles. The zeta potential represents the stability of colloidal dispersion. Table 3 shows the dispersion properties of $\mathrm{nZnO}$ suspension which is gotten as described above.

2.2. Experimental Setup. The osmometer self-developed comprised a pressure control system (composed of a pressure controller, an air pressure pump, and a pressure gauge), a temperature control system (a constant temperature sink), an infiltration chamber, and an automatic collector. The various parts of the system were connected by plexiglass hollow tubes to form a closed system (Figure 2). Osmotic pressure could be adjusted from $0.1 \mathrm{MPa}$ to $0.5 \mathrm{MPa}$ using a pneumatic pump. 


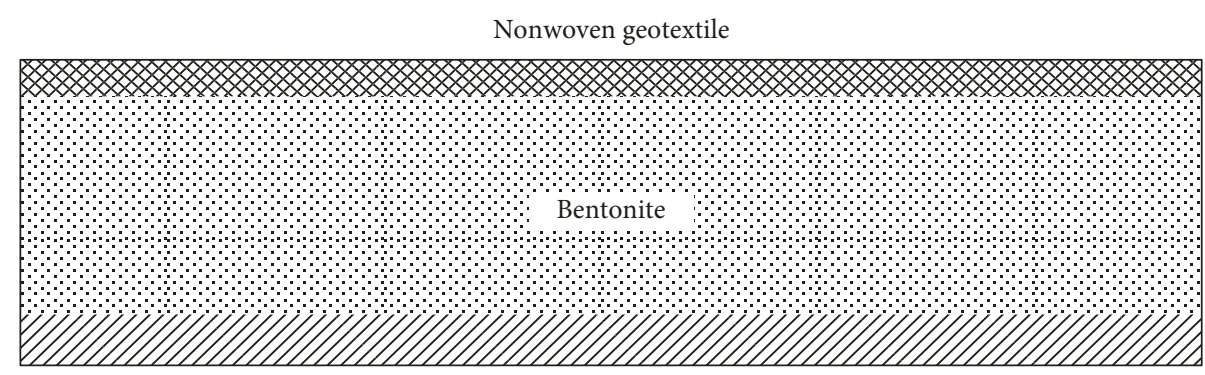

Woven geotextile

FIGURE 1: Structural representation of the GCL.

Table 3: The basic properties of $\mathrm{nZnO}$ suspensions.

\begin{tabular}{lcccccc}
\hline Component & State & Particle distribution range & Dispersive medium & pH & Zeta potential & Concentration \\
\hline $\mathrm{nZnO}$ & Pure white uniform colloid & $2 \sim 40 \mathrm{~nm}$ & Deionized water & $10 \sim 11$ & $37 \mathrm{mV}$ & $50 \mathrm{mg} / \mathrm{L}$ \\
\hline
\end{tabular}

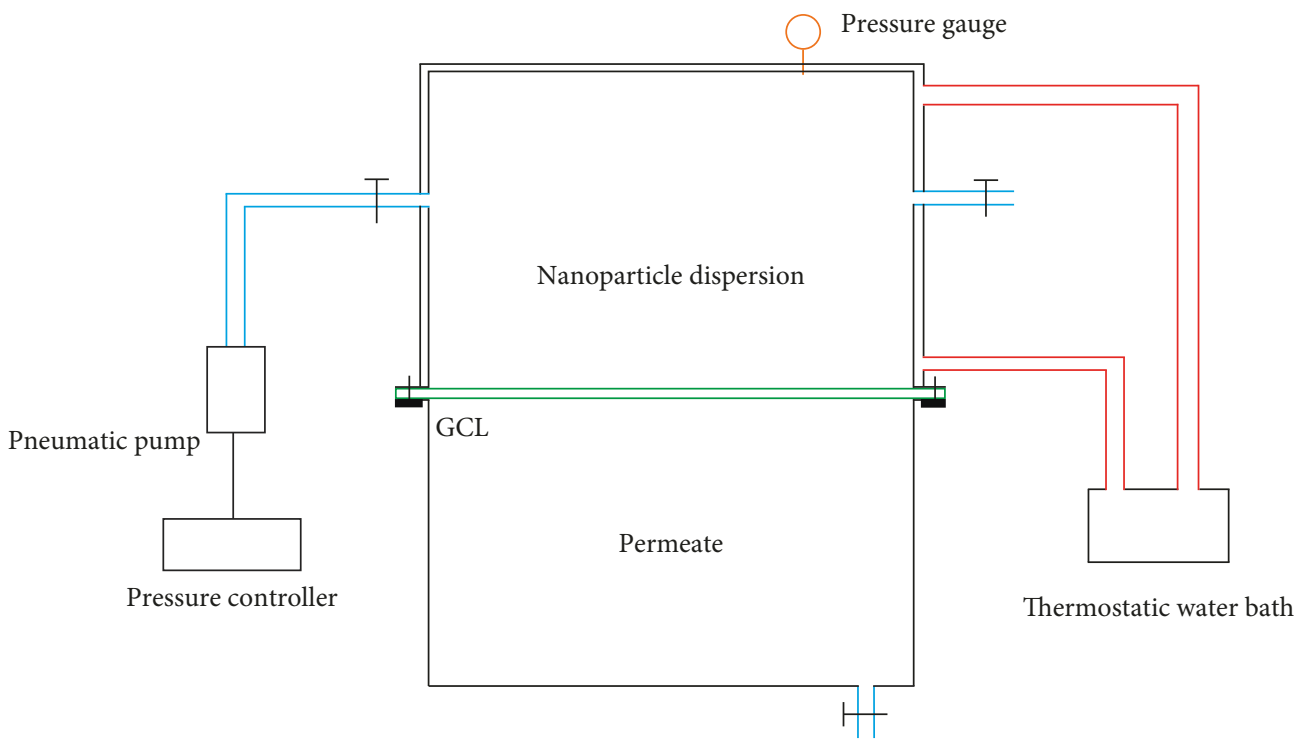

FIGURE 2: Schematic diagram of GCLs permeameter.

2.3. Experimental Methods. To investigate the effects of varying osmotic pressure on the migration of $\mathrm{nZnO}$ particles in GCLs, five osmotic pressure levels were set according to the water level of landfill leachate. Table 4 shows the experimental parameters.

The experiment steps were as follows:

(1) Inject 20 pore volumes (PV, obtained by dividing exudate volume by GCLs pore volume) of deionized water into the infiltration chamber and infiltrate GCLs under a specific pressure.

(2) Mix nZnO granule stock solution with a suitable amount of background solution at a specific proportion and use a magnetic stirrer to stir for $3 \mathrm{~h}$ to ensure complete mixing.

(3) Inject uniformly mixed $\mathrm{nZnO}$ granule suspension into the infiltration chamber and set a corresponding osmotic pressure using the control system.

(4) Collect exudate every $1 / 3 \mathrm{PV}$.
TABLE 4: The parameters of experiment.

\begin{tabular}{lc}
\hline Experimental condition & Osmotic pressure \\
\hline Initial concentration $50 \mathrm{mg} / \mathrm{L}$ & \\
Ionic strength $1 \mathrm{mmol} / \mathrm{L}$ & From 0.1 to $0.5 \mathrm{MPa}$ \\
Organic content $1 \mathrm{mg} / \mathrm{L}$ & \\
Temperature $30^{\circ} \mathrm{C}$ &
\end{tabular}

Note. $\mathrm{C}=$ degrees centigrade.

(5) When 15 PV of exudate have been collected, elute $\mathrm{nZnO}$ particles that have been intercepted in the GCLs using 5 PV of deionized water.

(6) Collect the exudate at the bottom of the infiltration chamber by using an automatic collector and centrifuge tubes. All exudate samples obtained through infiltration and elution were collected in $5 \mathrm{~mL}$ centrifuge tubes.

(7) Measure $\mathrm{nZnO}$ particle concentration using ICP. 
Mark the concentration of $\mathrm{nZnO}$ particles before infiltrating GCLs as $C_{0}$ and that in the exudate collected after infiltrating GCLs as $C$. After the experiment has been completed, adopt the PV number as the abscissa and $C / C_{0}$ as the ordinate to plot a breakthrough curve (BTC) of $\mathrm{nZnO}$ particles. The maximum $C / C_{0}$ indicates maximum breakthrough equilibrium concentration $\left(C_{\max }\right)$. When at least three consecutive $\mathrm{C} / \mathrm{C}_{0}$ values are $\geq 95$ percent of the $C_{\max }$, it is defined as equilibrium in the breakthrough curve. The smallest $\mathrm{PV}$ value corresponding to $C_{\max }$ is defined as the equilibrium critical PV.

The compression test and infiltration test of GCLs were conducted with Chinese standard for soil test method (GB/T 50123-1999).

2.4. Theoretical Model. This study adopted a two-site kinetic attachment model in porous media proposed by van Genuchten and Wagenet [27] to analyze the migration of nanoparticles in porous media. The dimensionless form of the two-site kinetic attachment model can be expressed as:

$$
\begin{aligned}
\frac{\partial C_{1}}{\partial T}+(\beta R-1) \frac{\partial C_{1}}{\partial T}+ & (1-\beta) R \frac{\partial S}{\partial T}=\frac{1}{\operatorname{Pe}} \frac{\partial^{2} C_{1}}{\partial X^{2}}-\frac{\partial C_{1}}{\partial X}, \\
(1-\beta) R \frac{\partial S}{\partial T} & =\omega\left(C_{1}-S\right)
\end{aligned}
$$

where $C_{1}$ is the relative concentration $C / C_{0} ; \beta$ is the fraction of instantaneous retardation, denoting the distribution of instantaneous equilibrium and rate-limited site types; $\omega$ is the Damköhler number, which is the ratio between the retention time and the characteristic absorption time in hydrodynamics; $T$ is the number of pore volumes; $S$ is the total adsorption; Pe is the Péclet number, which is a dimensionless number designating the ratio between the convection rate and the diffusion rate; and $R$ is the retardation factor, reflecting the characteristics of retardation nanoparticles exhibit in migrating through the porous medium.

\section{Analysis of Experimental Results}

3.1. BTC of nZnO Particles under Varying Osmotic Pressures. Figure 3 shows the breakthrough curve of $\mathrm{nZnO}$ particles at varying pressures. The parameters of the BTC are shown in Table 5.

When the pressure rises from $0.1 \mathrm{MPa}$ to $0.5 \mathrm{MPa}$, the critical PV rises from 7.5 to 9.8. As pressure increases, the maximum equilibrium concentration $C_{\max }$ declines, and the interception ratio increases. When the osmotic pressure rises from $0.1 \mathrm{MPa}$ to $0.5 \mathrm{MPa}$, the maximum equilibrium concentration $C_{\max }$ drops from $40.04 \mathrm{mg} / \mathrm{L}$ to $20.145 \mathrm{mg} / \mathrm{L}$. At the same time, the total rejection rate of $\mathrm{nZnO}$ particles in GCLs increases from $48.21 \%$ to $82.04 \%$. In the experiments, the interception ratio was $82.04 \%$ under an osmotic pressure of $0.5 \mathrm{MPa}$, meaning that a substantial quantity of $\mathrm{nZnO}$ particles deposited in GCLs, with only $17.96 \%$ of the particles migrating from GCLs and only $0.18 \%$ of the particles migrating out of the GCLs. Both the maximum equilibrium
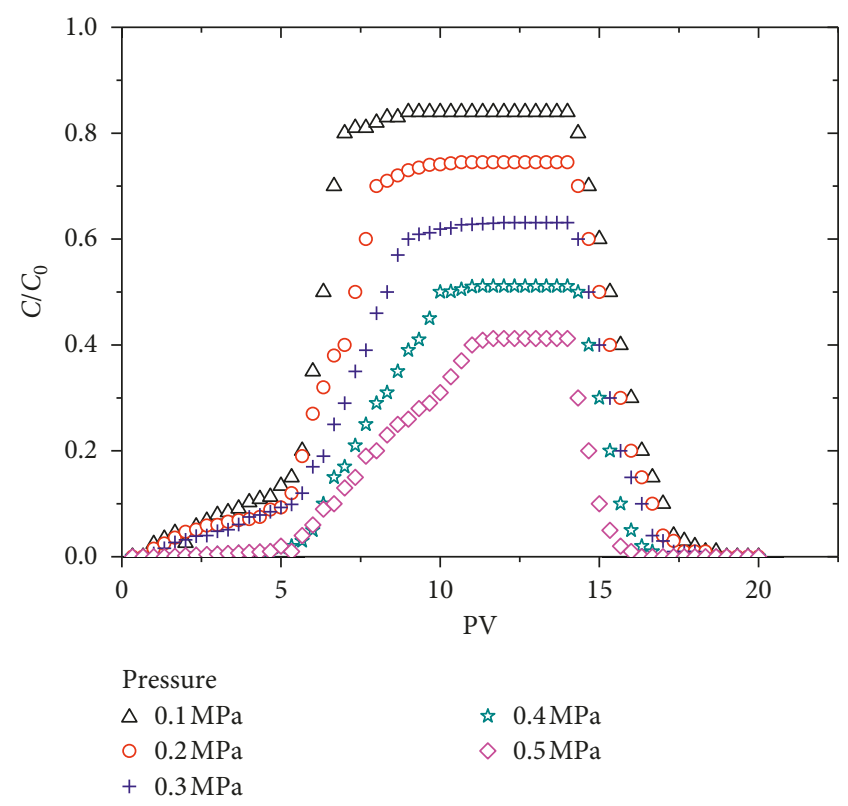

FIgUre 3: BTC of $\mathrm{nZnO}$ particles under different osmotic pressures.

concentration $C_{\max }$ and interception ratio of $\mathrm{nZnO}$ particles under varying osmotic pressures indicated that the migration properties of $\mathrm{nZnO}$ particles in GCLs weakened when osmotic pressure increased.

\subsection{Effect of Varying Osmotic Pressure on Transportation Parameters}

3.2.1. Effect of Osmotic Pressure on the Stability of $n \mathrm{ZnO}$ Suspension. The test results of the particles size and zeta potential of the $\mathrm{nZnO}$ particle suspensions under different osmotic pressures are shown in Figure 4. The results indicated that pressure can cause $\mathrm{nZnO}$ particles to grow in size and agglomerate and reduce the scattering stability of the $\mathrm{nZnO}$ suspension. The test results revealed that when the osmotic pressure rose from $0.1 \mathrm{MPa}$ to $0.5 \mathrm{MPa}$, the zeta potential of the $\mathrm{nZnO}$ suspension rose from $-38.6 \mathrm{mV}$ to $-34.2 \mathrm{mV}$ and the size of $\mathrm{nZnO}$ particles increased by $5.8 \%$ from $317.1 \mathrm{~nm}$ to $335.5 \mathrm{~nm}$.

3.2.2. Effect of Osmotic Pressure on the Microstructure and Infiltration Properties of GCLs. Under pressure changes, the porosity ratios of GCLs change accordingly. This study performed a compression test on the GCLs to obtain a compression curve (Figure 5). When the pressure rose from $0.1 \mathrm{MPa}$ to $0.5 \mathrm{MPa}$, the GCLs porosity ratio decreased from 7.9 to 2.1. Specifically, at the initial stage of pressure application (0.05-0.20 MPa), the extent of change in the porosity ratio was relatively small because the pressure exerted relatively little force on the internal structure of GCLs. When the pressure increased from $0.2 \mathrm{MPa}$ to $0.35 \mathrm{MPa}$, relatively high pressure accelerated the GCLs porosity change rate, causing the porosity ratio to decrease by $62.5 \%$ (i.e., from 6.4 to 2.4 ), the pressure had a relatively 
TABle 5: Parameters of the BTC.

\begin{tabular}{lcccc}
\hline $\begin{array}{l}\text { Osmotic } \\
\text { pressure } \\
(\mathrm{MPa})\end{array}$ & Critical PV & $C_{\max }(\mathrm{mg} / \mathrm{L})$ & Total rejection rate (\%) & Desorption rate/reversible rejection rate (\%) \\
\hline 0.1 & 7.5 & 40.04 & 48.21 & 3.91 \\
0.2 & 7.8 & 40.515 & 57.00 & 2.78 \\
0.3 & 8.3 & 30.095 & 65.48 & 0.89 \\
0.4 & 8.4 & 30.54 & 75.38 & 0.18 \\
0.5 & 9.8 & 20.145 & 82.04 & 0.84 \\
\hline
\end{tabular}
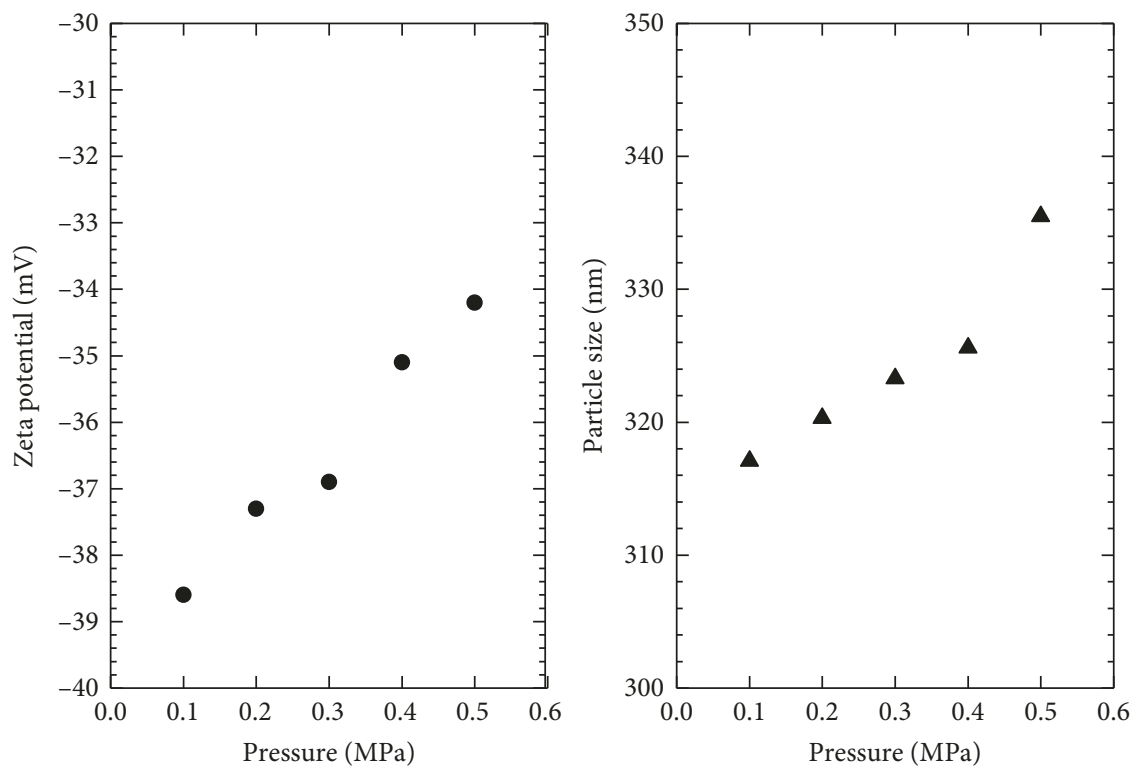

Figure 4: (a) Zeta potential of nZnO suspension and (b) particle size of nZnO particles under different osmotic pressures.

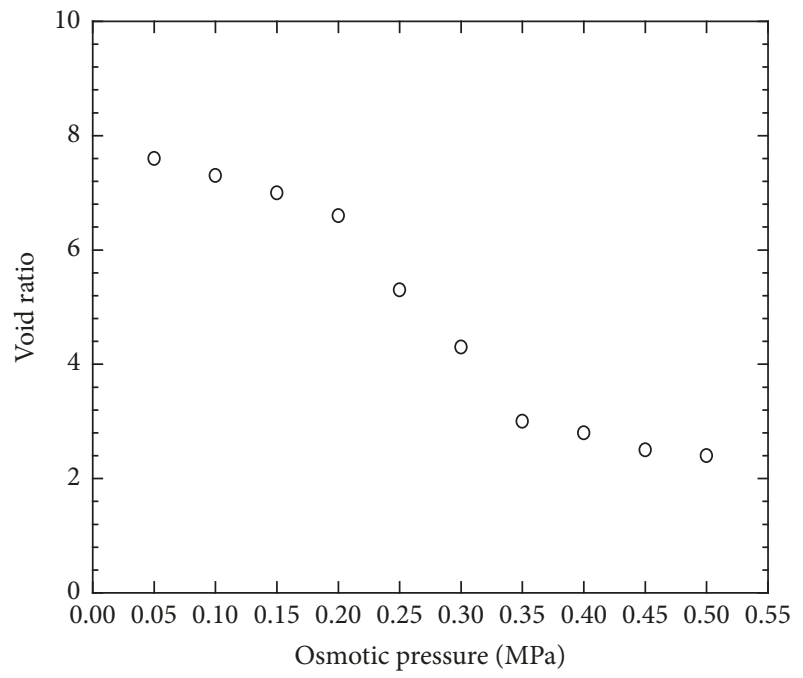

Figure 5: GCLs compression curve.

large effect on the internal structure of GCLs. Finally, because the consolidation effect in the preceding stages had fully compressed the GCLs, changes in the GCLs porosity ratio were inconspicuous in the last stage of compression (0.35-0.5 MPa), and the porosity ratio remained between 2.0 and 2.4. Therefore, osmotic pressure exerted notable effects on GCLs microstructure.

The GCLs infiltration coefficients under varying pressures were tested using the infiltration test (Figure 6). The test results indicated that, with continual increases in osmotic pressure, GCLs infiltration coefficients continually decreased. When the osmotic pressure reached $0.35 \mathrm{MPa}$, the extent of change in infiltration coefficients was reduced.

The effect of pressure on the migration performance of $\mathrm{nZnO}$ particles in GCLs has a certain effect. The migration performance of $\mathrm{nZnO}$ particles deteriorates as the pressure increases. This is mainly due to the fact that $\mathrm{nZnO}$ particles tend to agglomerate in suspension as the pressure increases, and the nZnO particle size becomes larger, which is not conducive to its migration in porous media. In addition, pressure affects the microstructure of GCLs. Pressure causes the GCLs pores to decrease and the permeability to decrease. The retention of $\mathrm{nZnO}$ particles by GCLs is enhanced.

\subsection{Mechanism of Effect of Osmotic Pressure on $n Z n O$ Particle} Migration in GCLs. The two-site model was used to fit the breakthrough curves of $\mathrm{nZnO}$ particles in GCLs under different osmotic pressures. The results of the simulation are shown in Figure 7. The coincidence between the fitting curve and the measured data is good. When the pressure was lower 


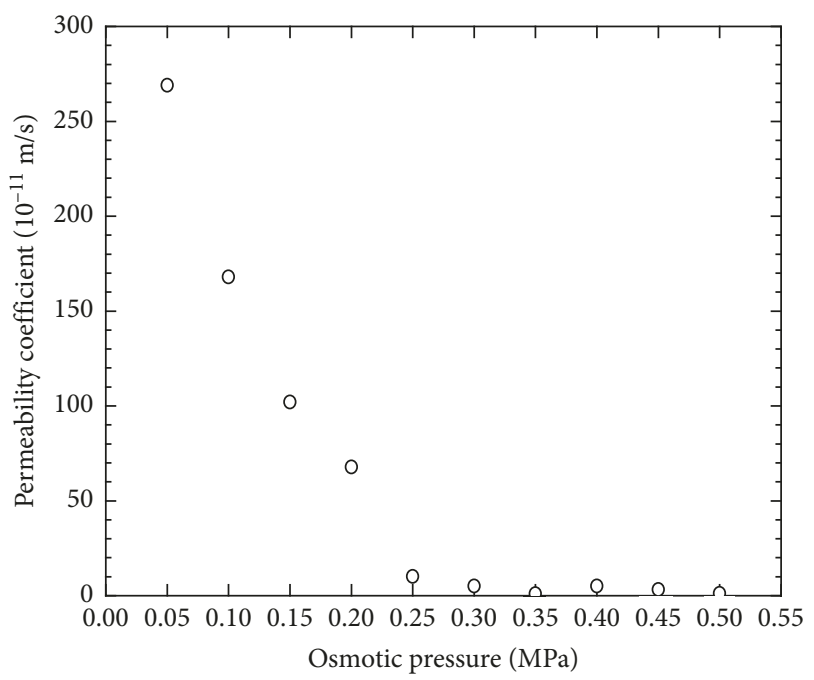

FIGURE 6: GCLs permeability coefficient under different osmotic pressures.

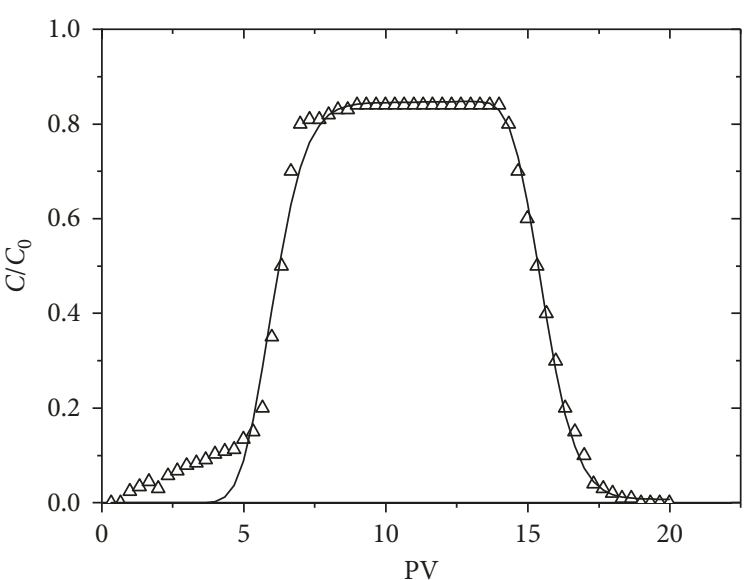

$\triangle$ Experimental data

— Simulation curve

(a)

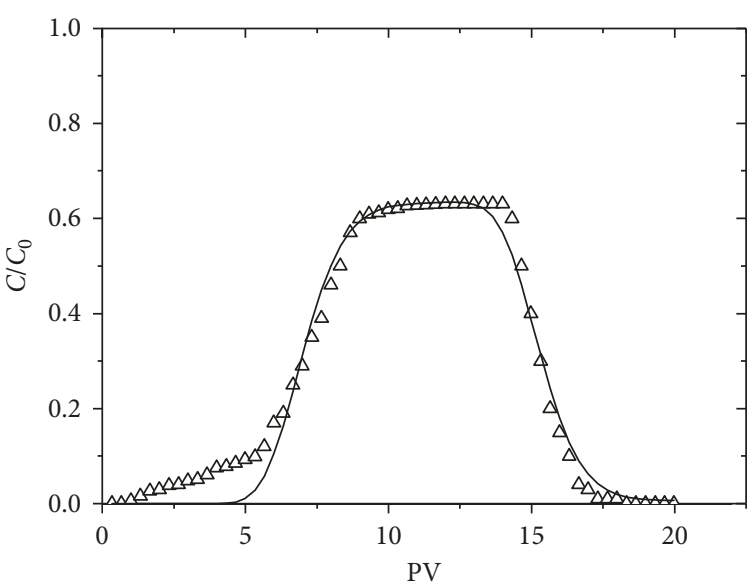

$\Delta \quad$ Experimental data

- Simulation curve

(c)

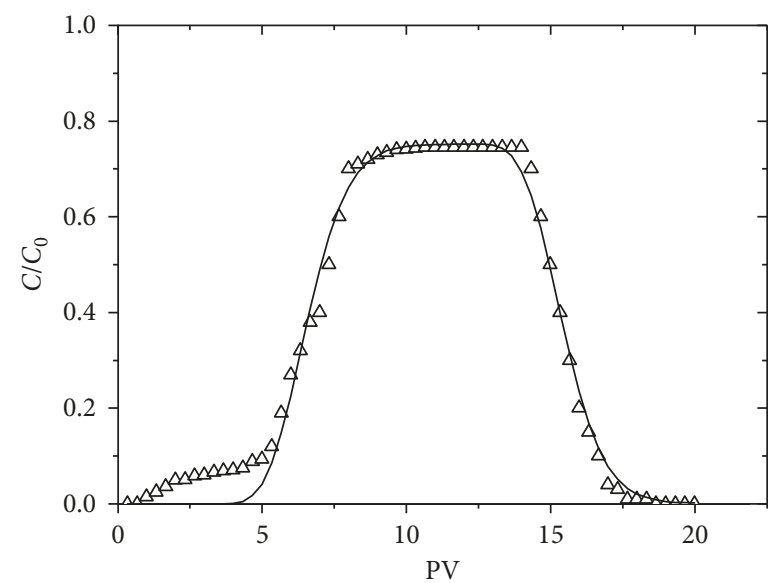

$\Delta$ Experimental data

— Simulation curve

(b)

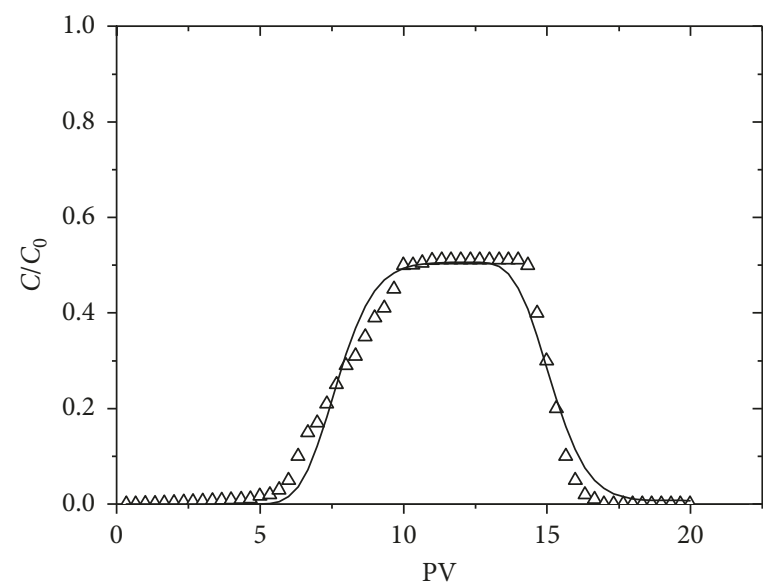

$\triangle$ Experimental data

— Simulation curve

(d)

Figure 7: Continued. 


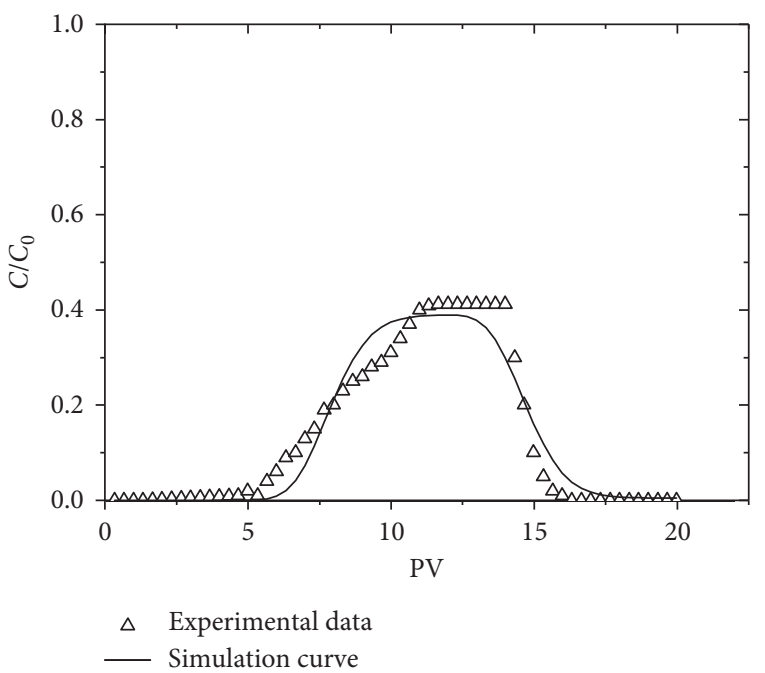

(e)

Figure 7: The two-site model simulation results. Pressure: (a) $0.1 \mathrm{MPa}$; (b) $0.2 \mathrm{MPa}$; (c) $0.3 \mathrm{MPa}$; (d) $0.4 \mathrm{MPa}$; (e) $0.5 \mathrm{MPa}$.

than $0.3 \mathrm{MPa}$, the infiltration coefficients and void ratio of GCLs decrease quickly with increase of pressure. So, in the first $5 \mathrm{PV}$, the coincidence between the fitting curve and the measured data is relatively low. This indicates that the twosite model can describe the migration process very well. In addition, the coefficient of correlation $\left(R^{2}\right)$ also notes that the two-site model has a better fitting effectiveness for the migration process, as shown in Table $6, R^{2}$ are all above 0.945 . Of the four dimensionless parameters, pressure had relatively large influences on the $\mathrm{Pe}, R$, and $\omega$. Specifically, $\mathrm{Pe}$ dropped when pressure rose, which indicated that the convection effect of $\mathrm{nZnO}$ particles weakened in the GCLs. This phenomenon happened because pressure reduced GCLs porosity so that the flow rate of the suspension slowed in the GCLs. $R$ was positively correlated with pressure. Greater values of $R$ indicated that the nanoparticles encountered greater retardation when nanoparticles migrated in the porous medium. Therefore, the retardation effect of GCLs on nZnO particles became increasingly conspicuous as pressure increased.

3.4. Maximum Migration Distance of Nanoparticles. The maximum migration distance $\left(L_{\max }\right)$ of nanoparticles in porous media is defined as the migration distance when $99 \%$ of nanoparticles (i.e., $c / c_{0}=0.01$ ) are trapped. The two-site model can accurately describe the migration process of $\mathrm{nZnO}$ particles in GCLs. Therefore, we adopted the two-site model to simulate the relationship between $C / C_{0}$ of $\mathrm{nZnO}$ particles and the migration distance $(z)$ in GCLs under different experimental conditions by the CXTFIT module of the STANMOD software and to acquire the $L_{\max }$. The results of the simulation are shown in Figure 8. From the simulation results, the correlativity between $L_{\max }$ and osmotic pressure is negative. It is also proved that the migration properties of nZnO particles in GCLs drop down with the osmotic pressure increasing.
TABLE 6: The fitting values of the dimensionless parameters in the two-site model.

\begin{tabular}{lccccc}
\hline $\begin{array}{l}\text { Osmotic pressure } \\
(\mathrm{MPa})\end{array}$ & $\mathrm{Pe}$ & $R$ & $\beta$ & $\omega$ & $R^{2}$ \\
\hline 0.1 & 251.2448 & 61.9311 & 0.4014 & 0.0632 & 0.988 \\
0.2 & 229.2961 & 128.8189 & 0.3910 & 0.0981 & 0.988 \\
0.3 & 69.3585 & 170.7667 & 0.3244 & 0.5214 & 0.979 \\
0.4 & 62.3821 & 385.2743 & 0.3065 & 1.1122 & 0.977 \\
0.5 & 36.7632 & 501.5935 & 0.3874 & 2.3723 & 0.945 \\
\hline
\end{tabular}

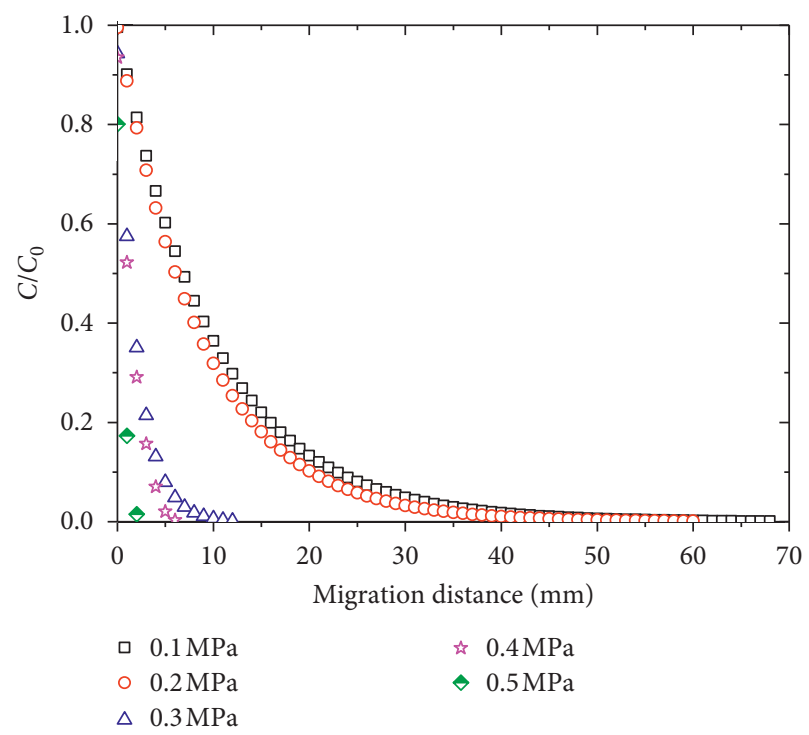

FIgURE 8: Migration distance simulation results.

\section{Conclusion}

Along with increasing pressure, the zeta potential among $\mathrm{nZnO}$ particles decreased, the maximum energy barrier 
$\left(\Phi_{\max }\right)$ reduced gradually, the agglomeration properties of $\mathrm{nZnO}$ strengthened, and the tension-induced interception of $\mathrm{nZnO}$ particles in GCLs increased.

Along with increasing pressure, GCLs pores were compressed, the infiltration coefficient of GCLs reduced, and the interception effect of GCLs on $\mathrm{nZnO}$ particles strengthened.

The two-site model can accurately describe the migration process of $\mathrm{nZnO}$ particles in GCLs. The migration properties of $\mathrm{nZnO}$ particles in GCLs drop down with the osmotic pressure increasing.

The correlativity between $L_{\max }$ and osmotic pressure is negative. It is also proved that the migration properties of $\mathrm{nZnO}$ particles in GCLs drop down with the osmotic pressure increasing.

Because of the complex environmental conditions of landfills, the actual conditions of such sites could not be accurately simulated in this study. However, the aforementioned results can serve as a reference for future research on the migration behaviors and mechanisms of nanoparticles in landfills.

\section{Data Availability}

The data used to support the findings of this study are included within the article.

\section{Conflicts of Interest}

The authors declare that they have no conflicts of interest.

\section{Acknowledgments}

This investigation was supported by the National Natural Science Foundation of China (projects nos. 41672274 and 41002093); the Fundamental Research Funds for the Central Universities (projects no. 22120180233); and Opening fund of State Key Laboratory of Geohazard Prevention and Geoenvironment Protection (Chengdu University of Technology) (project no. SKLGP 2014K013). The authors are extremely grateful for the financial support from these four organizations.

\section{References}

[1] M. F. Peterson, "Progress in preparation and application of one-dimensional nano zinc oxide," Journal of Materials Engineering, vol. 43, no. 2, pp. 103-112, 2015.

[2] P. Sun, A. Shijirbaatar, J. Fang, G. Owens, D. Lin, and K. Zhang, "Distinguishable transport behavior of zinc oxide nanoparticles in silica sand and soil columns," Science of the Total Environment, vol. 505, pp. 189-198, 2015.

[3] D. Collins, T. Luxton, N. Kumar, S. Shah, V. K. Walker, and V. Shah, "Assessing the impact of copper and zinc oxide nanoparticles on soil: a field study," Plos One, vol. 7, no. 8, p. e42663, 2012.

[4] H. A. Jeng and J. Swanson, "Toxicity of metal oxide nanoparticles in mammalian cells," Journal of Environmental Science and Health Part A Toxic/hazardous Substances and Environmental Engineering, vol. 41, no. 12, pp. 2699-2711, 2006.
[5] A. Gojova, B. Guo, R. S. Kota, J. C. Rutledge, I. M. Kennedy, and A. I. Barakat, "Induction of inflammation in vascular endothelial cells by metal oxide nanoparticles: effect of particle composition," Environmental Health Perspectives, vol. 115, no. 3, pp. 403-409, 2007.

[6] W. Lin, Y. Xu, C.-C. Huang et al., "Toxicity of nano- and micro-sized $\mathrm{ZnO}$ particles in human lung epithelial cells," Journal of Nanoparticle Research, vol. 11, no. 1, pp. 25-39, 2009.

[7] X. Deng, Q. Luan, W. Chen et al., "Nanosized zinc oxide particles induce neural stem cell apoptosis," Nanotechnology, vol. 20, no. 11, article 115101, 2009.

[8] D. Wang, M. Paradelo, S. A. Bradford et al., "Facilitated transport of $\mathrm{Cu}$ with hydroxyapatite nanoparticles in saturated sand: effects of solution ionic strength and composition,” Water Research, vol. 45, no. 18, pp. 5905-5915, 2011.

[9] G. S. Yazici, B. Alan, E. Adar, and M. S. Bilgili, "The impact of nanoparticles on aerobic degradation of municipal solid waste," Waste Management and Research, vol. 35, no. 4, pp. 426-436, 2017.

[10] S. C. Bolyard, D. R. Reinhart, and S. Santra, "Behavior of engineered nanoparticles in landfill leachate," Environmental Science and Technology, vol. 47, no. 15, p. 8114, 2013.

[11] I. A. Khan, N. D. Berge, T. Sabo-Attwood, P. Lee Ferguson, and N. B. Saleh, "Single-walled carbon nanotube transport in representative municipal solid waste landfill conditions," Environmental Science and Technology, vol. 47, no. 15, pp. 8425-433, 2013.

[12] Y. Zhang, P. Yang, and S. Xue, "Researching advances in transportation of nanomaterial contaminants in soil," Environmental Engineering, vol. 3, pp. 88-91, 2015, in Chinese.

[13] X. Liu, D. M. O'Carroll, E. J. Petersen, Q. Huang, and C. L. Anderson, "Mobility of multiwalled carbon nanotubes in porous media," Environmental Science \& Technology, vol. 43, no. 21, pp. 8153-8158, 2009.

[14] N. T. Mattison, D. M. O'Carroll, R. K. Rowe, and E. J. Petersen, "Impact of porous media grain size on the transport of multi-walled carbon nanotubes," Environmental Science and Technology, vol. 45, no. 22, pp. 9765-9775, 2011.

[15] Y. Liang, S. A. Bradford, J. Simunek, H. Vereecken, and E. Klumpp, "Sensitivity of the transport and retention of stabilized silver nanoparticles to physicochemical factors," Water Research, vol. 47, no. 7, pp. 2572-2582, 2013.

[16] K. Wang, J. Liu, L. Liu, and D. Sun, "Biocompatibility of graphene oxide," Nanoscale Research Letters, vol. 6, no. 1, pp. 1-8, 2011.

[17] D. Bouchard, W. Zhang, and X. Chang, "A rapid screening technique for estimating nanoparticle transport in porous media," Water Research, vol. 47, no. 12, p. 4086, 2013.

[18] I. G. Godinez and C. J. Darnault, "Aggregation and transport of nano-TiO2 in saturated porous media: effects of $\mathrm{pH}$, surfactants and flow velocity," Water Research, vol. 45, no. 2, pp. 839-851, 2011.

[19] D. H. Lin, X. Tian, F. Wu, and B. Xing, "Fate and transport of engineered nanomaterials in the environment," Journal of Environmental Quality, vol. 39, no. 6, p. 1896, 2010.

[20] T. Rahman, J. George, and H. J. Shipley, "Transport of aluminum oxide nanoparticles in saturated sand: effects of ionic strength, flow rate, and nanoparticle concentration," Science of the Total Environment, vol. 499, no. 5, pp. 565-571, 2014.

[21] A. Braun, E. Klumpp, R. Azzam, and C. Neukum, “Transport and deposition of stabilized engineered silver nanoparticles in water saturated loamy sand and silty loam," Science of the Total Environment, vol. 535, p. 102, 2015. 
[22] D. Wang, C. Su, W. Zhang et al., "Laboratory assessment of the mobility of water-dispersed engineered nanoparticles in a red soil (Ultisol)," Journal of Hydrology, vol. 519, pp. 1677-1687, 2014

[23] S. P. Kulizhskiy, S. V. Loiko, Y. N. Morgalev, G. I. Istigechev, A. V. Rodikova, and T. A. Maron, "Investigation of platinum and nickel nanoparticles migration and accumulation in soils within the South eastern part of West Siberia," Nano Hybrids and Composites, vol. 13, pp. 115-122, 2017.

[24] W. Zhang, Experimental and Numerical Study on Water/ Leachate Transport in Landfill of Municipal Solid Waste.D., Zhejiang University, Hangzhou, China, 2007, in Chinese.

[25] J. Liu and X. J. Kong, "Seismic stability and permanent displacement analysis of a solid waste landfill slope containing geomembrane," Rock and Soil Mechanics, vol. 25, no. 5, pp. 778-782, 2004.

[26] G. K. Wang and Y. X. Yang, "Infection of different ultra audible frequency and temperature to dispersive property of ZnO nanometre granule," Sichuan Textile Technology, 2005, in Chinese.

[27] M. Th. van Genuchten and R. J. Wagenet, "Two-site/tworegion models for pesticide transport and degradation: theoretical development and analytical solutions," Soil Science Society of America Journal, vol. 53, no. 5, pp. 1303-1310, 1989. 


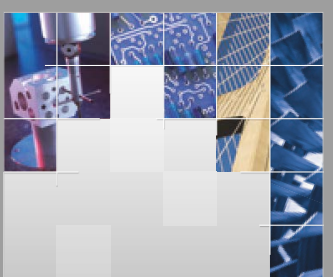

\section{Enfincering}
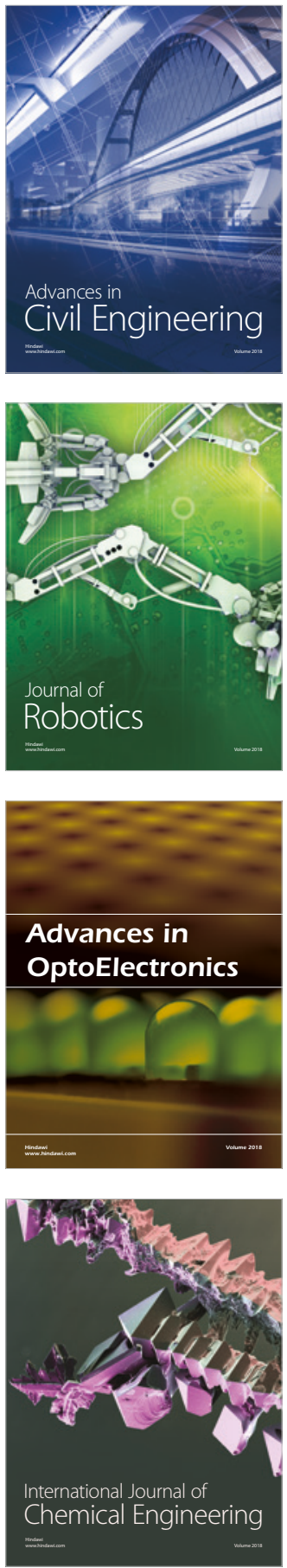

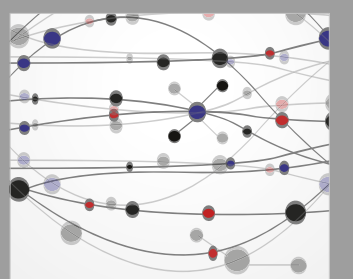

\section{Rotating \\ Machinery}

The Scientific World Journal

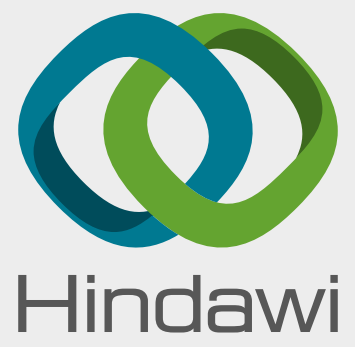

Submit your manuscripts at

www.hindawi.com
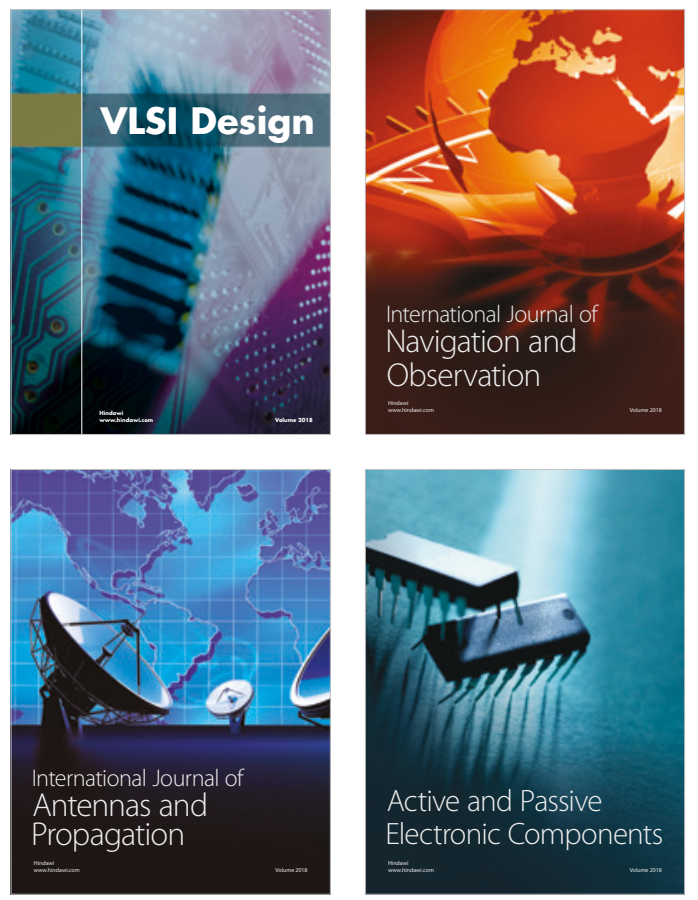
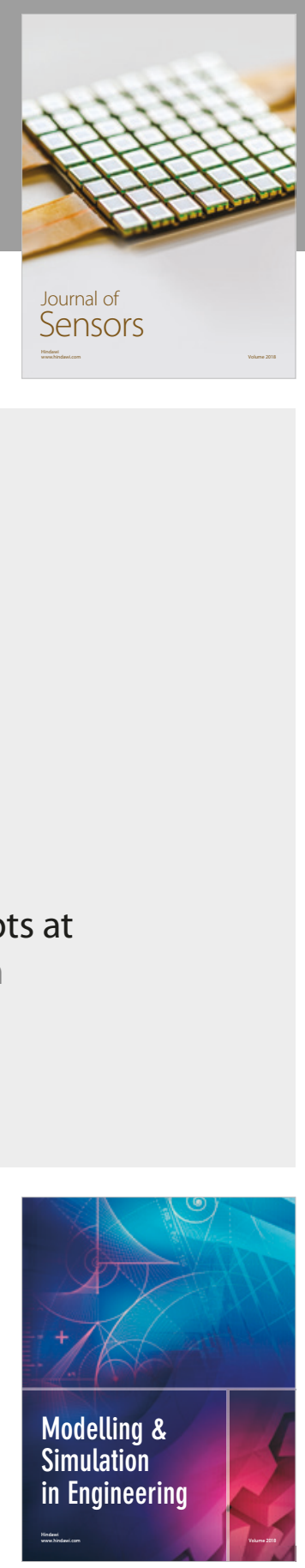

\section{Advances \\ Multimedia}
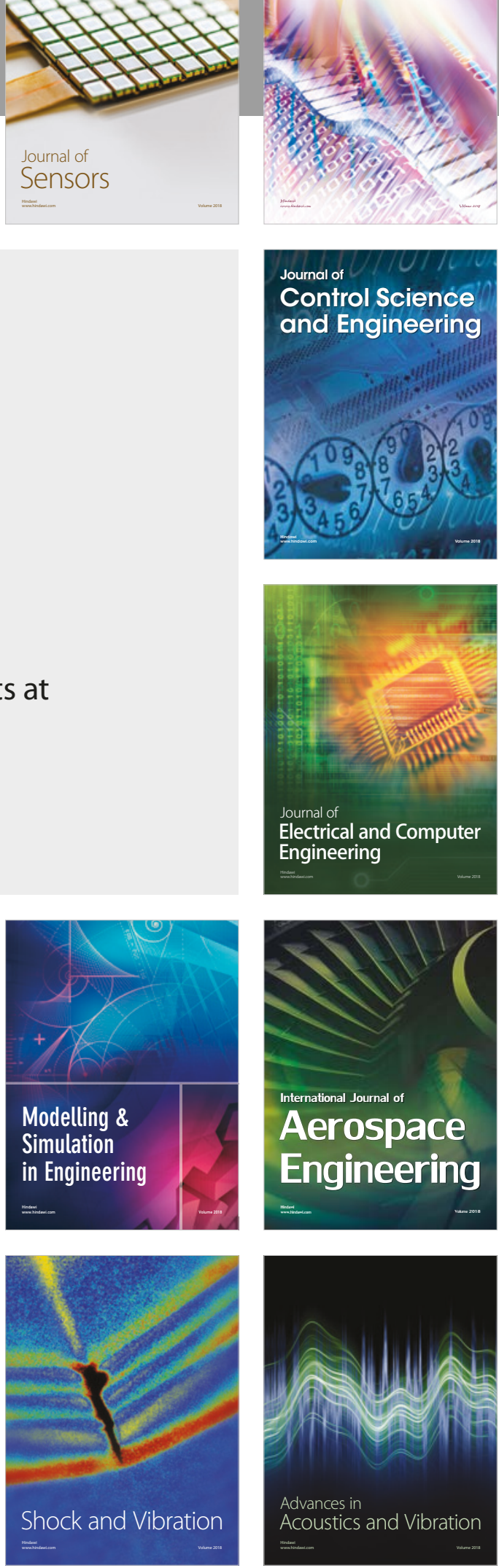